\title{
Characterizing Multiscale Effects of Climatic Factors on the Temporal Variation of Vegetation in Different Climatic Regions of China
}

hongfen zhu ( $\nabla$ hongfzh@163.com )

Shanxi Agricultural University https://orcid.org/0000-0002-9220-9017

Haoxi Ding

Shanxi Agricultural University

Rutian Bi

Shanxi Agricultural University

Meiting Hou

China Meteorological Administration (CMA) Training Centre

\section{Research Article}

Keywords: Percentage area of significant coherence (PASC), Bivariate wavelet coherency (BWC), Multivariate wavelet coherence (MWC), NDVI, Scale

Posted Date: September 3rd, 2021

DOl: https://doi.org/10.21203/rs.3.rs-425456/v1

License: (9) This work is licensed under a Creative Commons Attribution 4.0 International License. Read Full License

Version of Record: A version of this preprint was published at Theoretical and Applied Climatology on January 15th, 2022. See the published version at https://doi.org/10.1007/s00704-022-03928-6. 
1 Running title: Multiple temporal scale of climate on vegetation

2

3 Characterizing multiscale effects of climatic factors on the temporal variation of vegetation in different climatic regions of China

5

Hongfen Zhu ${ }^{\text {a,b }}$, Haoxi Ding a , Rutian Bi ${ }^{\text {a,b,*, }}$, Meiting Hou ${ }^{c}$

7

8 a College of Resources and Environment, Shanxi Agricultural University, Taigu, Shanxi 030801,

9 China

10 b National Experimental Teaching Demonstration Center for Agricultural Resources and 11 Environment, Shanxi Agricultural University, Taigu, Shanxi, 030801, China

$12{ }^{\mathrm{c}}$ China Meteorological Administration (CMA) Training Centre, Beijing, 100081, China

15 * Corresponding author: Rutian Bi

16 E-mail: sxndbrt@163.com 
Abstract: Vegetation dynamic is sensitive to climatic warming, and is affected by individual or combined climatic factors at different temporal scale with different intensity. Previous studies have unraveled the relationships between vegetation condition and individual climatic factors; however, it is unclear whether the effects of single or combined climatic factors on vegetation dynamic was dominant for different temporal scales, vegetation types, and climatic regions. The objective of this study was to explore the scale-specific univariate and multivariate controls on vegetation over the period 1982-2015 using bivariate wavelet coherency (BWC), multiple wavelet coherence (MWC), and multiple empirical model decomposition (MEMD). The results indicated that the significant vegetation dynamics were mainly located at scales of $1,0.5$, and 0.3 years. The combined explanatory power of the seven climatic factors on the vegetation were greater at the short-term and long-term scales, while the individual climatic factor might affect vegetation dynamic in the seasonal and medium-term scales at some climatic regions. The combined effect of climatic factors in grassland of Tibetan Plateau (TP) and Tempera grassland of Inner Mongolia (TGIM) regions were the greatest, which were $65.06 \%$ and $59.53 \%$, respectively. The explanatory powers of climate for crop dynamics between temperate humid \& subhumid Northeast China (THSNC) and TP, warmtemperate humid \& subhumid North China (WHSNC) and subtropical humid Central \& South China (SHCSC), and TGIM and temperate \& warm-temperate desert of Northwest China (TWDNC) were equivalent, which were around 47\%, 45\%, and 39\%, respectively. Farming practices in cropland could alleviate the spatial variation of the relationships between climate and vegetation, while enhance the temporal difference of their relationships. Additionally, the dominant influencing factor among different regions varied greatly in the medium-term scale. Collectively, the results might provide alternative perspective for understanding vegetation evolution in response to climatic changes in China.

Keywords: Percentage area of significant coherence (PASC); Bivariate wavelet coherency (BWC); Multivariate wavelet coherence (MWC); NDVI; Scale 


\section{Introduction}

Vegetation, a primary component of terrestrial ecosystem, plays an important role in mitigating soil erosion, regulating terrestrial carbon balance, and providing food for living beings (Ding et al., 2020; Liu et al., 2018; Tong et al., 2016). Moreover, vegetation serves as a sensitive indicator for climatic changes and ecological environment (Sun et al., 2015). Therefore, understanding of vegetation dynamic and its relationships with climatic factors are necessary for reducing the uncertainty in exploring the vegetation feedback to global warming and accurately evaluating terrestrial carbon cycles (Chuai et al., 2020).

Previous studies related to vegetation dynamics and its relationships with long-term series of climatic factors from regional to global spatial scales have been performed, especially with the assistance of satellite-based normalized difference vegetation index (NDVI) (Li et al., 2020), which has been widely used in monitoring vegetation dynamic and exploring the relationships between vegetation and climate changes (He et al., 2012; Zewdie et al., 2017; Zhang et al., 2016). Majority of these studies focused on the original temporal scale, without considering that climatic variables exert an effect on vegetation with different intensity at different temporal scales and different times (Rathinasamy et al., 2019). Thus, quantifying the scale- and temporal-specific climatic driving factors on vegetation variability is necessary for unravelling the vegetation response to climate change.

The scale-dependent variation of climatic factors or the scale-specific relationships between vegetation and individual climatic factor were explored using ensemble empirical mode decomposition (EEMD) (Qi et al., 2019), wavelet transform (WT) (Liu and Menzel, 2016), or the combination of moving windows and linear correlation method (Ning et al., 2019). However, the mechanism of vegetation response to climatic variables is complex and may be concurrently affected by climatic factors. Although the relative importance of mixed climatic factors was quantified using the traditional methods, such as the multivariate regression analysis (Liu et al., 2018) and residual trend method (Sun et al., 2015), the neutralization effect at different scales and times may mislead the interpretation of vegetation variations. Meanwhile, previous studies (Gao et al., 2020; Liu and Menzel, 2016; Zhao and $\mathrm{Hu}, 2020)$ reported that the mechanism of vegetation response to climate differed with climatic region and vegetation type. Therefore, the effect of combined climatic factors on vegetation growth should be explored considering the temporal scales, 
climatic regions, and vegetation types.

Based on bivariate wavelet coherency (BWC), Hu and Si (2016) proposed a multivariate wavelet coherence (MWC) method, which can be used to detect multivariate relationships in the temporalscale domain than general multivariate methods because of its ability for identifying localized multivariate relationships. The MWC method has been widely used in a range of areas such as hydrology (Gu et al., 2020), soil science (Centeno et al., 2020), environmental science (Zhao et al., 2018), climate (Song et al., 2020), and economics (Sen and Chaudhury, 2019) for untangling scalespecific and localized multivariate relationships for both spatial and temporal series of data irrespective of stationarity or non-stationarity. Because of its wide applicability we expect that the MWC can be used in ecological science to explore scale-specific and localized effects of multiple climatic factors on vegetation distribution. Therefore, we hypothesize that the response of vegetation to climatic factors differs with temporal scale, climatic condition and vegetation type, which can be identified by the wavelet methods including BWC and MWC.

China has the land area of approximately $960 \times 10^{4} \mathrm{~km}^{2}$ covering approximately $50^{\circ}$ of latitude and $62^{\circ}$ of longitude, and has extremely diverse climatic conditions (Bai et al., 2020). For clearly unraveling the relations between climate and vegetation across China, different climatic regions were partitioned. The objective of this study was to explore the single or mixed climatic factors on the vegetation growth under different temporal scales, climatic regions, and vegetation types. Specifically, the univariate relationships between monthly NDVI and single climatic factor were explored using BWC; the multivariate relationships between NDVI and the combined climatic factors were characterized using both MWC and multivariate empirical mode decomposition (MEMD).

\section{Material and methods}

\subsection{Study area}

Based on the climatic indexes of active accumulated temperature, aridity index and frost-free period, China can be divided into seven climatic regions (Zhao, 1983), including Temperate humid \& subhumid Northeast China (THSNC1), Warm-temperate humid \& subhumid North China (WHSNC2), Subtropical humid Central \& South China (SHCSC3), Tropic humid South China (THSC), Tempera grassland of Inner Mongolia (TGIM4), Temperate \& warm-temperate desert of Northwest China (TWDNC5), and Tibetan Plateau (TP6). In the study, the THSC region was 
combined into SHCSC3 region because of the least area of THSC and the similar variations of vegetation in the both regions. The six climatic regions are shown in Fig. 1a, and the corresponding climatic indices are shown in Table 1 . The aridity index gradually increased from east to west, while the active accumulated temperature and frost-free period gradually increased from north to south in the east of China.

\subsection{Data sources}

A total of 2,474 meteorological stations across China from 1982 to 2015, including the daily temperature, precipitation, sunshine duration, relative humidity, and wind speed, were collected from Climatic Data Center, National Meteorological Information Center (https://data.cma.cn/). After eliminating the meteorological stations with deficient data, the monthly mean temperature (MT), highest temperature (HT), lowest temperature (LT), accumulated precipitation (AP), sunshine duration (SSD), relative humidity (RH), or wind speed (WS) were obtained from each station.

The vegetation index of NDVI were derived from the global inventory modeling and mapping studies (GIMMS) obtained from the national oceanic and atmospheric administration (NOAA) satellites boarded on the advanced very high resolution radiometer (AVHRR) sensor (https://ecocast.arc.nasa.gov/data/pub/gimms/). The meteorological stations where the highest quality of NDVI accounted for more than $85 \%$ (quality flags for 1982-2015) were selected, and their monthly NDVI data from 1982 to 2015 were extracted. Annual land cover map of MODIS product (MCD12Q1) from 2001 to 2015 across China were obtained from the level-1 and atmosphere archive and distribution system (LAADS) (https://ladsweb.modaps.eosdis.nasa.gov/). Only meteorological stations where land use types did not change from 2001 to 2015 were retained in this study. Because the meteorological stations were mainly located in the grassland or cropland, only two vegetation types were considered (Fig. 1b).

Based on vegetation type, 564 meteorological stations located in the grassland and cropland were selected. The spatially-averaged time series of NDVI, MT, HT, LT, AP, SSD, RH, and WS were calculated over the period 1982-2015, corresponding to two vegetation types in six climatic regions. 2.3 Bivariate wavelet coherency (BWC) and Multiple wavelet coherence (MWC)

The MWC between the response variable $\mathrm{Y}$ and predictor variables $\mathrm{X}\left(\mathrm{X}=\left[X_{1}, X_{2}, \ldots, X_{m}\right]\right)$ at the scale-time (or scale-location) domain $(\mathrm{s}, \tau)$ is defined as $(\mathrm{Hu}$ and $\mathrm{Si}, 2016)$ : 


$$
\rho_{m w c}^{2}(s, \tau)=\frac{\overleftrightarrow{W}^{Y, X}(s, \tau) \overline{\overleftrightarrow{W}^{Y, X}(s, \tau)}}{\overleftrightarrow{W}^{X, X}(s, \tau) \overleftrightarrow{W}^{Y, Y}(s, \tau)}
$$

When only one variable $\left(\mathrm{X}_{1}\right)$ was included in $\mathrm{X}$, Eq. (2) is the equation for BWC, which is expressed as:

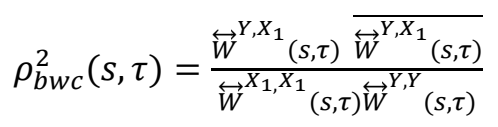

where $\overleftrightarrow{w}^{Y, X}(s, \tau)$ is a vector of the smoothed cross-wavelet power spectra, and $\overline{\overleftrightarrow{W}^{Y, X}(s, \tau)}$ is its complex conjugate. The $\overleftrightarrow{w}^{Y, X}(s, \tau)$ is written as:

$$
\overleftrightarrow{w}^{Y, X}(s, \tau)=\left[\overleftrightarrow{w}^{Y, X_{1}}(s, \tau) \quad \overleftrightarrow{w}^{Y, X_{2}}(s, \tau) \quad \cdots \quad \overleftrightarrow{w}^{Y, X_{m}}(s, \tau)\right]
$$

The $\overleftrightarrow{w}^{X, X}(s, \tau)$ is a series of the smoothed auto and cross-wavelet power spectra for multivariable $\mathrm{X}$, which is expressed as:

$$
\overleftrightarrow{W}^{X, X}(s, \tau)=\left[\begin{array}{cccc}
\overleftrightarrow{W}^{X_{1}, X_{1}}(s, \tau) & \overleftrightarrow{W}^{X_{1}, X_{2}}(s, \tau) & \cdots & \overleftrightarrow{W}^{X_{1}, X_{m}}(s, \tau) \\
\overleftrightarrow{W}^{X_{2}, X_{2}}(s, \tau) & \overleftrightarrow{W}^{X_{2}, X_{2}}(s, \tau) & \cdots & \overleftrightarrow{W}^{X_{m}, X_{m}}(s, \tau) \\
\vdots & \vdots & \vdots & \overleftrightarrow{W}^{X_{m}, X_{m}}(s, \tau)
\end{array}\right]
$$

$\overleftrightarrow{W}^{Y, Y}(s, \tau)$ is the smoothed auto-wavelet power spectra for response variable Y. Both BWC and MWC at 95\% significance level are calculated using the Monte Carlo method (Grinsted et al., 2004). A detailed description of BWC can be found in previously studies (Grinsted et al., 2004), and detailed description of MWC can be found in $\mathrm{Hu}$ and $\mathrm{Si}$ (2016).

2.4 Multivariate empirical mode decomposition (MEMD)

The MEMD is a multivariate extended empirical mode decomposition (EMD) algorithm. To overcome the disadvantage of generating different number of intrinsic mode function (IMF) among multivariate temporal data, MEMD could align common IMFs present within multivariate data. The detailed procedures of MEMD can be found in other publications (Hu et al., 2013; Rehman and Mandic, 2010).

\subsection{Data processing}

The local wavelet spectra of NDVI for two vegetation types in six climatic regions were calculated to assess the NDVI variations. The BWC between NDVI and each individual climatic factor and MWC between NDVI and the combined climatic factors were calculated, and percentage area of significant coherence (PASC) (Hu et al., 2017; Zhu et al., 2016) was calculated to assess the relative effect of controlling factors on NDVI. Meanwhile, MEMD combined with the squared multiple correlation coefficient was performed for multivariate temporal series. The scales of each 
IMF for NDVI and climatic factors were calculated using Hilbert transform, and the mean scales were obtained to represent the characteristic scales. The variance contribution of each IMF to the total variation in NDVI was calculated as the ratio of the variance of each IMF to the variance of the original temporal series of NDVI.

\section{Results}

\subsection{Pearson's correlation between NDVI and climatic factors}

The Pearson's correlation coefficients between NDVI and climatic factors in six climatic regions and two vegetation types are presented in Table 2. Obviously, temperature and precipitation had consistently positive correlations with vegetation growth. The duration of sunshine and relative humidity also had significant and positive effect on vegetation, while wind speed had significant and negative relationships with NDVI except in the climatic region of TP6. Based on the correlation coefficients, the dominant climatic factors under different regions and vegetation types were similar, and temperature had the greatest correlation with NDVI across China.

\subsection{Local wavelet spectra of NDVI}

There were distinguishable seasonal patterns across the multiple temporal scales in the local wavelet spectrum of NDVI (Fig. 2). The variation of NDVI around 1-year scale was discerned for the two vegetation types in the six climatic regions. Meanwhile, the seasonality patterns of significant variation around 0.5-year scale were detected for grassland and cropland in the regions of THSNC1, TGIM4, and TP6. The discernable pattern around 0.3-year scale was found in cropland of WHSNC2 and SHCSC3. Additionally, the significant variations around 0.5- and 0.3-year scales entangled with each other after 1995 year in the cropland of SHCSC3. However, in TWDNC5, the seasonal patterns less than 1-year scale were not detected at all.

3.3 Univariate control of climatic factor on NDVI by BWC

The scale- and temporal-specific correlations between NDVI and single climatic factor in grassland are shown in Fig. 3. Because of the similar relationships between NDVI and AT or HT or LT, the BWC between NDVI and HT or LT is not presented. The wavelet coherency between single climatic factor and NDVI were significant around the 1-year scale except the relations between NDVI and SSD in SHCSC3, and the relations between NDVI and SSD or RH or WS in TP6. The effect of precipitation on NDVI around 0.5-year scale was greater than that of temperature for grassland in the regions of THSNC1, WHSNC2, TGIM4, and TP6. Meanwhile, the interannual 
effects of precipitation on vegetation were also detected locally or universally in grassland of WHSNC2, TGIM4, TWDNC5, and TP6.

Overall significant correlations existed in the relationships between NDVI and climatic factor. Therefore, the controls of climatic factors on vegetation could be divided into four temporal scales, including $\leq 1$ years (seasonal), 1-4 years, 4-8 years, and $>8$ years. The influential strength of each individual climatic factors on grass growth is shown in Table 3 . For the scales of $\leq 1$ year, precipitation played a leading role in grassland activity across China except the region of TWDNC5. For scales of 1-4 years, precipitation controlled the grass growth in the North China of TGIM4 and TWDNC5, while temperature was the main factor in the rest of China. For scales of 4-8 and > 8 years, the dominant factors varied among TP, MT, AP, RH, and SSD in different climatic regions. However, the impact of precipitation on grass growth was noticeable at all scales across the entire China.

The scale- and temporal-specific correlations between NDVI and single climatic factors in cropland are shown in Fig. 4. The relationships between single climatic factor and NDVI were captured by the significant wavelet coherency at the temporal scales of $0.5,1,4$, and 8 years. The impact of each individual climatic factor on crop growth is shown in Table 4 . For scales $\leq 1$ year, precipitation had a dominantly positive effect on crop growth except the TGIM4 and TWDNC5 regions, while RH in TGIM4, and WS in TWDNC5 played a dominant role in the crop growth. For the scales of 1-4 years, temperature was the dominant driver for crop growth except precipitation in THSNC1 region. For the scales of $4-8$ and $>8$ years, the dominant influencing factors varied among the climatic factors in different climatic regions.

3.4 Scale- and temporal-specific multivariate control of climatic factors on NDVI by MWC

To compare the effect of individual climatic factors on NDVI, the MWC was used to explore the combined effect of climatic factors on NDVI. Obviously, the climatic factors explained very well of the NDVI variations around scales of 1 and 0.5 years (Fig. 5). Although the explanatory capacity of single climatic factor on grass growth was limited in the region of SHCSC3, the combined climatic factors could prominently improve the explanatory capacity on vegetation growth at scales of $1-4$ and $>8$ years.

The PASC values of MWC between NDVI and combined climatic factors for grassland and cropland are shown in Table 5. Obviously, the mixed effect of climatic factors could slightly increase 
the control of single climatic factor on vegetation growth at scales of $\leq 1$ and $1-4$ years in most regions, and obviously improved the effect of single climatic factor at scales of $>8$ years. However, the combined effect was limited in the scales of 4-8 years, with improved effects being observed only in the grassland of TGIM4 and TP6, and the cropland of TWDNC5, where the combined effects at scales of $\leq 1$ year were weaker than that of single climatic driver. It is worth pointing out that the combined effect of climatic factors on vegetation dynamics were greater than that of single climatic factor at the overall temporal scale. In summary, the leading factor for grass variation at scales of $\leq 1$ year was precipitation for TGIM4 and TP6 regions, and was the combination of climate for the other regions; at the scales of 4-8 years, they were $\mathrm{RH}$, precipitation, SSD, combination of climate, precipitation, and the combination for the six climatic regions, respectively; at scales of $1-4$ and $>8$ years, they were the combined climatic factors. For crop growth, the dominant factors at the scales of $\leq 1$ years were RH and WS for TGIM4 and TWDNC5, respectively, and were the climatic combination for the other regions; at scales of 4-8 years, they were HT, WS, precipitation, HT, combined factors, and LT for the six climatic regions, respectively; at the scales of $1-4$ and $>8$ years, the results for cropland were consistent with those for grassland.

The PASC of combined climatic factors ranged from $37 \%$ to $65 \%$ at the overall temporal scale in grassland, and the effects in different regions ranked in an increase order as SHCSC3 < TWDNC5 $<$ THSNC1 < WHSNC2 < TGIM4 < TP6. The PASC of combined climatic factors ranged from 39\% in TGIM4 and TWDNC5 to $45 \%$ in WHSNC2 and SHCSC3 and 47\% in THSNC1 and TP6 at overall temporal scales in cropland. Therefore, depending on the explanatory power of climatic factors, the agricultural production areas can be classified into four regions of WHSNC2-SHCSC3, TGIM4-TWDNC5, THSNC1, and TP6. The variation of PASC among different climatic regions was obviously lower for cropland than that for grassland, while the variation of PASC among different temporal scales was greater for cropland than that for grassland.

\subsection{Comparison of MWC with MEMD}

The decomposed components of NDVI by MEMD indicated that MEMD had the advantage to extract information on large trends (see supplementary Fig.S1 and Fig.S2). The averaged scales of NDVI and climatic factors (MT, HT, LT, AP, SSD, RH, and WS) and the variance contribution of each IMF towards original variance of NDVI are presented in Table 6. The shortest scale was 0.99 year represented by IMF1, which contributed the majority variance of above $80 \%$. The result agrees 
with that analyzed by wavelet transform which showed that the majority of NDVI variations occurred at scale of around 1 year (Fig. 2).

Coefficients of determination between each scale component of NDVI and climatic factors at the corresponding scale demonstrated that the control of climatic factors on NDVI were the greatest at temporal scales around 1 and $>8$ year (see supplementary Fig.S3), which were similar to the results from MWC. However, temperature played a dominant role around 1-year scale across China by MEMD, while precipitation had the leading effect at the scales of $\leq 1$ year at most climatic regions by MWC.

\section{Discussion}

4.1 Vegetation variation at different temporal scales

The impact of land cover change on vegetation growth is complicated because it does not only depend on the intensity but also on the type of land-cover change (Gao et al., 2020). In the study, the land types during 1982-2000 were not considered because the major shift in land use types have taken place after 2000, such as urbanization caused the conversion from croplands to construction land, the Grain for Green Projection caused the conversion from cropland to forest. Thus, to precisely evaluate the vegetation-climate variation at multiple temporal scales, the land types maintained from 2001 to 2015 were extracted in the study to minimize the heterogeneity of anthropogenic factors on vegetation.

The local variation of grass and crop NDVI were significant around the 1-year scale across the variation around 0.5 -year scale was insignificant, while the variation around 0.3 -year scale was 
summer maize) uniformly applied in this area (Yan et al., 2020). In the TWDNC5 region, because of the lowest NDVI value across the whole year and the driest climatic conditions (Zhao and $\mathrm{Hu}$, 2020), the vegetation growth did not display the seasonal variations at scales of <1 years. Notably, the seasonal pattern around 0.5-year scale was prominent in the THSNC1, TGIM4, and TP6 regions, which might be attributed to the difference between vegetation season and non-vegetation season (Zhou et al., 2020). The mingled seasonal patterns at 0.5- and 0.3-year scales in the cropland of SHCSC3 might be attributed to the mixed cropping system of double-rice cropping and rice-wheat cropping after 1995 year (Wu et al., 2013; Zhang et al., 2015). Therefore, the vegetation variation was dominant by the 1-year scale across the entire China, the variation at 0.5 -year scale was found in the temperate area and Tibetan Plateau with distinct difference between vegetation season and non-vegetation season during one year, and the significant variation at 0.3 -year scale was found generally under the cropland in the major crop producing area of the Southeast China (WHSNC2 and SHCSC3) with multiple cropping system.

\subsection{Effect of single climatic factor on NDVI at multiple temporal scales}

Previously studies reported that precipitation, temperature, solar radiation, and relative humidity were significantly correlated with vegetation growth in China (Sun et al., 2020; Yang and Zhang, 2014; Zhao and Hu, 2020). The climatic factors, including MT, HT, LT, AP, SSD, RH, and WS, were selected in the present study. We observed that the correlation between temperature and vegetation was positive at scales $>0.5$ years and was negative at scales $\leqslant 0.5$ years. Temperature exerted either dominantly positive effect or negative effect on vegetation growth at some scales was in agreement with previous observation in Southwest China (Liu and Menzel, 2016). The noticeable positive relationships between temperature and vegetation at scales larger than 0.5 -year might be attributed to more carbohydrate consumption and subsequently enhancement of daytime photosynthesis persistently, which resulted from the nighttime warming optimizing both root and leaf respiration of plants (Yuan et al., 2020). The negative effects of temperature on vegetation at less than 0.5-year scale were probably associated with the short-time limited water availability (Jiang et al., 2020), resulted from the increasing evaporation because of the increase in the highest temperature, constrained photosynthetic activities and aggravated plant respiration, and thus inhibited plant growth. Therefore, temperature exerted different effects on vegetation growth at different temporal scales. 

was different from the results from Southwest Germany (Liu and Menzel, 2016), which might be attributed to the different climatic conditions between Germany and China. However, the positive correlation between precipitation and NDVI was observed in the Yangtze River and Yellow River Basin at some temporal scales (Zhang et al., 2020). Although precipitation was not the greatest influencing factor for grass growth based on the Pearson's correlation coefficient, it played a leading role across the entire China at overall temporal scales and seasonal scale except the TWDNC5 region. Precipitation was not the leading factor for grass growth at the seasonal scale ( $\leq 1$ years) in TWDNC5, but it had a critical effect at the scales of 1-4 and 4-8 years, and overall temporal scales. In TGIM4 region, precipitation had a critical effect on grass growth at any temporal scales, which was consistent with previous finding that water availability dominated grass productivity in the region (Zhao and $\mathrm{Hu}, 2020)$. For cropland at the seasonal scale ( $\leq 1$ years), precipitation also played a leading role in the major crop producing areas (THSNC1, WHSNC2, and SHCSC3) and TP6, and RH had the dominant effect on crop productivity in TGIM4. In TWDNC5 region, precipitation seemed to exert the dominant influence on crop growth only at the scales of 4-8 years, probably because irrigation activities in the area disorganized the crop-precipitation relations, and the interannual variation of precipitation is greater than its intra-annual variation (Linscheid et al., 2020), which resulted in the leading effect at the scales of 4-8 years.

It is worth pointing out that SSD, which relates to solar radiation, was positively related with grass growth across the 1-year scale except the regions of SHCSC3 and TP6, while it had unstable effect on vegetation dynamic at other temporal scales. The local negative effect of SSD on vegetation might be related to the increased evaporation, and thus the increase of SSD caused water losses, further preventing plant from growth. In SHCSC3, SSD did not have stable relationships with grass condition around 1-year scale, which might be because of the discrepancy between SSD and the critical factor of temperature. The higher temperature resulted from closing to the equator, and the lower SSD. In TP6, SSD was slightly correlated with grass at 1-year scale, which agrees with a previous finding (Zhao and $\mathrm{Hu}, 2020$ ) that SSD explained less in alpine grasslands than that in temperate grasslands. The result might be attributed to the complex topology in TP6, which resulted in the large variations in SSD. 
in TP6. The complex topology in TP6, which makes the spatial distribution of climatic conditions much more heterogeneous, resulted in the varied mechanism of vegetation-climate dynamics. Meanwhile, the response of alpine grass to climate, which was distributed in TP6, was different from the temperate grassland. The slightly weak effect of relative humidity on crop productivity in THSNC1 might be attributed to the irrigation activities for crop in the area.

The WS exerted negative influence on vegetation productivity at 1 - and 0.5 - year scales, especially in temperate regions and Tibetan Plateau with the distribution of strong wind. The noticeable impacts of WS on the vegetation growth were probable due to mechanical destruction and excessive transpiration of plant resulted from strong wind (Gardiner et al., 2016), which is extremely injurious to a plant. However, the positive relationships between WS and vegetation were also observed in some localized time, because wind can increase turbulence in the atmosphere and availability of $\mathrm{CO}_{2}$ and thereby increased photosynthesis (Konrad et al., 2021). Unfortunately, the effect of WS on vegetation dynamic was not captured by Pearson's correlation coefficient in TP6 region.

We concluded that precipitation played a crucial role in affecting the seasonal variation of vegetation productivity resulted from the prominent effect around 0.5 -year scale, temperature played a leading role in affecting the variation of vegetation at the scales of 1-4 years. Thus, the leading single-factor is annual oscillation of temperature, combined with 0.5 -year intraannual dominance of precipitation. For scales of $4-8$ and $>8$ years, the dominant factor on vegetation varied with climatic regions and vegetation types, which implied that the mechanisms by which vegetation respond to single climatic factor were various among different regions and vegetation types at these temporal scales.

4.3 Combined effect of climatic factors on NDVI at multiple temporal scales

Our results showed that the interaction effects of multiple climatic factors on vegetation dynamic were stronger than the effect of individual climatic variables on NDVI at scales of $>8$ years. Such long-term climate variation may occur in the form of periodic atmospheric fluctuations (Linscheid et al., 2020), which might result in the long-term variation of NDVI. The combined climatic controls on NDVI were evaluated by previous studies. For example, Qu et al. (2020) distinguished the impacts of climate change and anthropogenic factors on vegetation dynamics based on partial derivation in the Yangtze River Basin, which were $70 \%$ and $30 \%$, respectively. However, it is 
unclear whether the effects of single or the combined climatic factors on vegetation dynamic was dominant for different temporal scales, vegetation types, and climatic regions. For scales of $\leq 1$ year and 4-8 years, single climatic factor played a dominant role in controlling the dynamic of vegetation in some climatic regions. The results confirmed that precipitation has a critical effect on grass productivity in Inner Mongolia and Tibetan Plateau (Zhao and Hu, 2020), and wind has a critical effect on crop productivity in Xinjiang at the seasonal scale. However, at the scales of 4-8 years, the climatic variables exerted different influences depending on the climatic regions and vegetation types, which might be attributed to the large variations at these temporal scales. For example, the climatic events of short-term concurrent hot and dry extreme (SCHDE) over the Pearl river basin was detected with larger variations at the temporal scale 4-8 years, which was negatively correlated with Niño3.4 index around scales of 4 year (Zhang et al., 2019). Meanwhile, variations in daily minimum temperature greater than $90^{\text {th }}$ percentile or daily maximum temperature greater than $90^{\text {th }}$ percentile were also dominant at temporal scales 4-8 years over the period 1960-2015 in Yangtze River Basin (Cui et al., 2019). At the scales of 1-4 and >8 years, the combination of climate exerted more important influence on vegetation growth across the entire China.

In our study, the explanatory capability of the climatic combination on grass growth ranked as SHCSC3 < TWDNC5 < THSNC1 (or WHSNC2) < TGIM4 < TP6; it ranked as TGIM4 (or TWDNC5) < WHSNC2 (or SHCSC3) < THSNC1 (or TP6) in terms of the effects on crop growth. The result indicated that socioeconomic condition is related to the dynamics of grass growth except TWDNC5 with the lowest NDVI values (Yao et al., 2019). The less variation of explanatory power among different regions demonstrated that tillage activities in cropland alleviated the spatial difference of climate-vegetation dynamics, and strengthened their temporal difference. Meanwhile, the greatest variation at scales of $4-8$ years implied that the climatic regions and vegetation types cannot be neglected in the analysis of vegetation growth at these temporal scales.

4.4 Comparison of MWC and MEMD on the multivariate relationships in ecology

The vegetation-climate relationships at scales around 1 year and $>8$ year were dominant, which were similar for both MWC and MEMD. The result demonstrated that both MWC and MEMD could unravel the dominant temporal scales of NDVI variation. However, the discrepancy of dominant factors at the seasonal scales among MEMD and MWC might be attributed to the shortage of vegetation-climate relations at 0.5-year scales for MEMD, where precipitation had a dominant 
effect on vegetation. MEMD can partition original series into limited temporal scales, and generally attributed dominant variance to the seasonal process in ecology, which was consistent with previous study finding that IMFs decomposed by EMD contained more variation in the seasonal cycle and less modulation in the interannual temporal scales for NDVI (Linscheid et al., 2020). In addition, other methods, such as multiple regression or local correlation methods, should be integrated into MEMD for yielding the combined scale-specific effect of climate on vegetation, or obtaining their localized multivariate relationships. Our result indicated that the residue decomposed by MEMD could represent the trend of vegetation growth. the temporal scales around 1 and $>8$ years, the distinction between both methods should be mastered and the appropriate one can be applied depending on the situation. The study paves a way for better understanding the scale-specific, localized temporal heterogeneity of vegetation growth response to climate variability, and the temporal evolution of vegetation dynamics at different climatic regions should be explored in the future.

\section{Conclusion}

The following conclusions were made:

(1) The vegetation variation at 1 -year scale could be captured across the entire China, vegetation variation at 0.5 -year scale was displayed in the temperate area and Tibetan Plateau with distinct difference between vegetation season and non-vegetation season during one year, and the significant variation at 0.3 -year scale happened generally in the major crop producing area of the Southeast China (WHSNC2 and SHCSC3) with multiple cropping system.

(2) For individual climatic factor, precipitation had a dominant effect on vegetation at the seasonal scale ( $\leq 1$ years) because of their significant relations around 0.5 -year scale, temperature had a dominant effect on vegetation at the scales of 1-4 years, and the leading factor on vegetation varied with climatic regions at the scales of $4-8$ and $>8$ years.

(3) The combination of climatic factors could promote the control on vegetation growth at the scales of 1-4 and >8 years across the entire China. Climatic regions and vegetation types cannot be neglected in the analysis of vegetation growth at the temporal scales of 4-8 year.

(4) The greatest mixed effect of climatic factors on grass growth was around $65 \%$ in Tibetan Plateau, and the greatest effect on crop growth was around $47 \%$ in the Tibetan Plateau and Northeast 
China. The effect of tillage activities on crop growth could alleviate the spatial variation of the vegetation-climate relations, while enhance the temporal difference of their relationships.

430 Acknowledgements This work has been supported financially by Natural Science foundation of Shanxi Province

431 (201801D221103), and National Key Research and Development Program of China (2018YFE0109600).

432 Author contribution Hongfen Zhu: conceptualization, methodology, software handling, formal analysis, validation, 433 and writing the manuscript. Haoxi Ding: data curation and revising the manuscript. Rutian Bi: supervision and revising the manuscript. Meiting Hou: data analysis and revising the manuscript.

435 Availability of data mand material The climate data are available from Climatic Data Center, National 436 Meteorological Information Center (https://data.cma.cn/). The NDVI were derived from the global inventory 437 modeling and mapping studies (GIMMS) obtained from the national oceanic and atmospheric administration 438 (NOAA) satellites boarded on the advanced very high resolution radiometer (AVHRR) sensor 439 (https://ecocast.arc.nasa.gov/data/pub/gimms/). Annual land cover map of MODIS product (MCD12Q1) from 2001 440 to 2015 across China were obtained from the level-1 and atmosphere archive and distribution system (LAADS) 441 (https://ladsweb.modaps.eosdis.nasa.gov/).

442 Code availability software: MATLAB, R.

\section{Declarations}

444 Ethics approval Not applicable.

445 Consent to participate Not applicable.

446 Consent to publication Not applicable.

447 Conflict of interest The authors declare no conflict of interest. 


\section{References}

Bai, L., Yang, L., Song, B., Liu, N. (2020) A new approach to develop a climate classification for building energy efficiency addressing Chinese climate characteristics. Energy 195: 116982.

Centeno, L. N. et al. (2020) Dominant Control of Macroporosity on Saturated Soil Hydraulic Conductivity at Multiple Scales and Locations Revealed by Wavelet Analyses. Journal of Soil Science and Plant Nutrition 20: 1686-1702.

Chuai, X. et al. (2020) Vegetation and climate zones based carbon use efficiency variation and the main determinants analysis in China. Ecological Indicators 111: 105967.

Cui, L. et al. (2019) Spatiotemporal extremes of temperature and precipitation during 1960-2015 in the Yangtze River Basin (China) and impacts on vegetation dynamics. Theoretical and Applied Climatology 136: 675-692.

Ding, Y., Li, Z., Peng, S. (2020) Global analysis of time-lag and -accumulation effects of climate on vegetation growth. International Journal of Applied Earth Observation and Geoinformation 92: 102179.

Gao, Q., Yu, M., Xu, H. (2020) Directional Climate Trend, Intensified Intraannual Variability, and Changes in Land Cover Drive the Dynamics of Vegetation Greenness in Peri-Urban China During 2001-2015. Journal of Geophysical Research: Biogeosciences 125: e2019JG005336.

Gardiner, B., Berry, P., Moulia, B. (2016) Review: Wind impacts on plant growth, mechanics and damage. Plant Science 245: 94-118.

Grinsted, A., Moore, J.C., Jevrejeva, S. (2004) Application of the cross wavelet transform and wavelet coherence to geophysical time series. Nonlinear Processes in Geophysics 11: 561-566.

Gu, X. et al. (2020) Identification and scaling behavior assessment of the dominant hydrological factors of nitrate concentrations in streamflow. Journal of Hydrologic Engineering 25: 06020002.

He, Y., Guo, X., Dixon, P., Wilmshurst, J.F. (2012) NDVI variation and its relation to climate in Canadian ecozones. Canadian Geographer-Geographe Canadien 56: 492-507.

Hou, W., Jiangbo, G., Shaohong, W., Erfu, D. (2015) Interannual Variations in GrowingSeason NDVI and Its Correlation with Climate Variables in the Southwestern Karst Region of China. Remote Sensing 7: 11105-11124.

Hu, W., Biswas, A., Si, B. (2013) Application of multivariate empirical mode decomposition for revealing scale-and season-specific time stability of soil water storage. Catena 113: 377-385.

Hu, W., Si, B.C. (2016) Technical note: multiple wavelet coherence for untangling scale-specific and localized multivariate relationships in geosciences. Hydrology and Earth System Sciences Discussions 20: 3183-3191.

Hu, W., Si, B.C., Biswas, A., Chau, H.W. (2017) Temporally stable patterns but seasonal dependent controls of soil water content: Evidence from wavelet analyses. Hydrological Processes 31: 3697-3707.

Jiang, W., Wang, L., Feng, L., Zhang, M., Yao, R. (2020) Drought characteristics and 
its impact on changes in surface vegetation from 1981 to 2015 in the Yangtze River Basin, China. International journal of Climatology 40: 3380-3397.

Konrad, W., Katul, G., Roth-Nebelsick, A. (2021) Leaf temperature and its dependence on atmospheric C02 and leaf size. Geological Journal 56: 866-885.

Li, H. et al. (2020) Using the Budyko hypothesis for detecting and attributing changes in runoff to climate and vegetation change in the soft sandstone area of the middle Yellow River basin, China. Science of the Total Environment 703: 135588.

Linscheid, N. et al. (2020) Towards a global understanding of vegetation-climate dynamics at multiple time scales. Biogeosciences Discussions 17: 945-962.

Liu, H., Zhang, M., Lin, Z., Xu, X. (2018) Spatial heterogeneity of the relationship between vegetation dynamics and climate change and their driving forces at multiple time scales in Southwest China. Agricultural \& Forest Meteorology 256-257: 10-21.

Liu, Z., Menzel, L. (2016) Identifying long-term variations in vegetation and climatic variables and their scale-dependent relationships: A case study in Southwest Germany. Global \& Planetary Change 147: 54-66.

Ning, T. et al. (2019) Interaction of vegetation, climate and topography on evapotranspiration modelling at different time scales within the Budyko framework. Agricultural and Forest Meteorology 275: 59-68.

Qi, X., Jia, J., Liu, H., Lin, Z. (2019) Relative importance of climate change and human activities for vegetation changes on China's silk road economic belt over multiple timescales. CATENA 180: 224-237.

Qu, S. et al. (2020) Distinguishing the impacts of climate change and anthropogenic factors on vegetation dynamics in the Yangtze River Basin, China. Ecological Indicators 108: 105724.

Rathinasamy, M. , Agarwal, A., Sivakumar, B., Marwan, N., Kurths, J. (2019) Wavelet analysis of precipitation extremes over India and teleconnections to climate indices. Stochastic Environmental Research and Risk Assessment 33: 20532069.

Rehman, N., Mandic, D. P. (2010) Multivariate empirical mode decomposition. Proceedings Mathematical Physical \& Engineering Sciences 466: 1291-1302.

Sen, A., Chaudhury, P. (2019) On the Co-movement of Crude, Gold Prices and Stock Index in Indian Market. arXiv preprint arXiv 1904: 05317.

Song, X. et al. (2020) Potential linkages of precipitation extremes in BeijingTianjin-Hebei region, China, with large-scale climate patterns using waveletbased approaches. Theoretical and Applied Climatology 141: 1251-1269.

Sun, C. et al. (2020) Tree-ring evidence of the impacts of climate change and agricultural cultivation on vegetation coverage in the upper reaches of the Weihe River, northwest China. Science of the Total Environment 707: 136160.

Sun, Y., Yang, Y., Zhang, L., Wang, Z. (2015) The relative roles of climate variations and human activities in vegetation change in North China. Physics and Chemistry of the Earth, Parts A/B/C 87-88: 67-78.

Tong, X. et al. (2016) Assessing future vegetation trends and restoration prospects 
in the Karst Regions of Southwest China. Remote Sensing 8: 357.

Wu, W. et al. (2013) Toward yield improvement of early-season rice: 0ther options under double rice-cropping system in central China. European Journal of Agronomy 45: 75-86.

Yan, Z. et al. (2020) Assessment of the sustainability of different cropping systems under three irrigation strategies in the North China Plain under climate change. Agricultural Systems 178: 102745.

Yang, S.W., Zhang, B. (2014) Vegetation cover change and its response to climatic factors using SPOT NDVI in Hedong of Gansu Province. Chinese Journal of Ecology 32: 455-461.

Yao, R., Cao, J., Wang, L., Zhang, W., Wu, X. (2019) Urbanization effects on vegetation cover in major African cities during 2001-2017. International Journal of Applied Earth Observation and Geoinformation 75: 44-53.

Yuan, M. et al. (2020) Vegetation green up under the influence of daily minimum temperature and urbanization in the Yellow River Basin, China. Ecological Indicators 108: 105760 .

Zewdie, W. , Csaplovics, E., Inostroza, L. (2017) Monitoring ecosystem dynamics in northwestern Ethiopia using NDVI and climate variables to assess long term trends in dryland vegetation variability. Applied Geography 79: 167-178.

Zhang, H., Wu, C., Hu, B.X. (2019) Recent intensification of short-term concurrent hot and dry extremes over the Pearl River basin, China. International Journal of Climatology 39: 4924-4937.

Zhang, W., Wang, L., Xiang, F., Qin, W., Jiang, W. (2020) Vegetation dynamics and the relations with climate change at multiple time scales in the Yangtze River and Yellow River Basin, China. Ecological Indicators 110: 105892.

Zhang, Y., Zhu, Z., Zhuo, L., Zeng, Z., Ciais, P. (2016) Seasonal and interannual changes in vegetation activity of tropical forests in Southeast Asia. Agricultural \& Forest Meteorology 224: 1-10.

Zhang, Z.S., Guo, L. J., Liu, T.Q., Li, C.F., Cao, C. G. (2015) Effects of tillage practices and straw returning methods on greenhouse gas emissions and net ecosystem economic budget in rice-wheat cropping systems in central China. Atmospheric Environment 122: 636-644.

Zhao, R. et al. (2018) Identifying localized and scale-specific multivariate controls of soil organic matter variations using multiple wavelet coherence. Science of the Total Environment 643: 548-558.

Zhao, S. (1983) A new scheme for comprehensive physical regionalization in China. Acta Geographica Sinica 50: 1-10.

Zhao, W., Hu, Z. (2020) Contributions of climatic factors to inter-annual variability of vegetation index in northern China grasslands. Journal of Climate 1: 175183.

Zhou, X. et al. (2020) Legacy effect of spring phenology on vegetation growth in temperate China. Agricultural and Forest Meteorology 281: 107845.

Zhu, H., Hu, W., Bi, R., Peak, D., Si, B. (2016) Scale- and location-specific relationships between soil available micronutrients and environmental factors 
583 Table 1 Six climatic regions of China and their chief climatic indices (Zhao, 1983).

\begin{tabular}{ccccc}
\hline Climatic regions & $\begin{array}{c}\text { Area } \\
\text { percentage (\%) }\end{array}$ & $\begin{array}{c}\text { Active accumulated } \\
\text { temperature }\left({ }^{\circ} \mathrm{C}\right)\end{array}$ & $\begin{array}{c}\text { Aridity } \\
\text { index (-) }\end{array}$ & $\begin{array}{c}\text { Frost-free } \\
\text { period (d) }\end{array}$ \\
\hline $\begin{array}{c}\text { Temperate humid \& subhumid } \\
\text { Northeast China (THSNC1) } \\
\text { Warm-temperate humid \& subhumid } \\
\quad \text { North China (WHSNC2) }\end{array}$ & 9.35 & $1400-3200$ & $0.5-1.2$ & $<145$ \\
$\begin{array}{c}\text { Subtropical humid Central \& South } \\
\text { China (SHCSC3) }\end{array}$ & 11.50 & $3200-4500$ & $0.5-1.5$ & $150-200$ \\
$\begin{array}{c}\text { Temperate grassland of Inner } \\
\text { Mongolia (TGIM4) }\end{array}$ & 6.94 & $>4500$ & $0.5-1.0$ & $\begin{array}{c}\text { whole } \\
\text { year }\end{array}$ \\
$\begin{array}{c}\text { Temperate \& warm-temperate desert } \\
\text { of Northwest China (TWDNC5) } \\
\text { Tibetan Plateau (TP6) }\end{array}$ & 17.90 & $2000-3000$ & $1.2-4.0$ & $<180$ \\
\hline & 29.89 & $3200-4500$ & $>4.0$ & $\begin{array}{c}\text { Around } \\
200\end{array}$ \\
\hline
\end{tabular}


Table 2 Correlation coefficients (R) between NDVI and climatic factors at the monthly scale.

\begin{tabular}{ccccccccc}
\hline $\begin{array}{c}\text { Vegetation } \\
\text { type }\end{array}$ & $\begin{array}{c}\text { Climatic } \\
\text { region }\end{array}$ & MT & HT & LT & AP & SSD & RH & WS \\
\hline \multirow{5}{*}{ Grassland } & THSNC1 & $0.88^{* *}$ & $0.87^{* *}$ & $0.89^{* *}$ & $0.78^{* *}$ & $0.41^{* *}$ & $0.66^{* *}$ & $-0.37^{* *}$ \\
& WHSNC2 & $0.88^{* *}$ & $0.87^{* *}$ & $0.90^{* *}$ & $0.85^{* *}$ & $0.39^{* *}$ & $0.58^{* *}$ & $-0.30^{* *}$ \\
& SHCSC3 & $0.63^{* *}$ & $0.64^{* *}$ & $0.63^{* *}$ & $0.57^{* *}$ & $0.15^{* *}$ & $0.39^{* *}$ & $-0.14^{* *}$ \\
& TGIM4 & $0.89^{* *}$ & $0.88^{* *}$ & $0.90^{* *}$ & $0.85^{* *}$ & $0.60^{* *}$ & $0.15^{* *}$ & $-0.34^{* *}$ \\
& TWDNC5 & $0.93^{* *}$ & $0.93^{* *}$ & $0.93^{* *}$ & $0.69^{* *}$ & $0.79^{* *}$ & $0.76^{* *}$ & $-0.57^{* *}$ \\
& TP6 & $0.88^{* *}$ & $0.88^{* *}$ & $0.88^{* *}$ & $0.93^{* *}$ & $0.31^{* *}$ & $0.22^{* *}$ & -0.08 \\
\hline \multirow{5}{*}{ Cropland } & THSNC1 & $0.90^{* *}$ & $0.90^{* *}$ & $0.91^{* *}$ & $0.82^{* *}$ & $0.49^{* *}$ & $0.15^{* *}$ & $-0.26^{* *}$ \\
& WHSNC2 & $0.90^{* *}$ & $0.89^{* *}$ & $0.91^{* *}$ & $0.78^{* *}$ & $0.45^{* *}$ & $0.36^{* *}$ & $-0.11^{*}$ \\
& SHCSC3 & $0.90^{* *}$ & $0.89^{* * *}$ & $0.90^{* *}$ & $0.74^{* *}$ & $0.36^{* *}$ & $0.15^{* *}$ & $-0.38^{* *}$ \\
& TGIM4 & $0.88^{* *}$ & $0.87^{* * *}$ & $0.90^{* *}$ & $0.75^{* *}$ & $0.63^{* *}$ & $0.71^{* *}$ & $-0.58^{* *}$ \\
& TWDNC5 & $0.89^{* *}$ & $0.89^{* *}$ & $0.90^{* *}$ & $0.58^{* *}$ & $0.84^{* *}$ & $0.57^{* *}$ & $-0.42^{* *}$ \\
& TP6 & $0.90^{* *}$ & $0.90^{* *}$ & $0.91^{* *}$ & $0.88^{* *}$ & $0.68^{* *}$ & $0.35^{* *}$ & -0.07 \\
\hline
\end{tabular}

${ }^{*}$ Significant at $P<0.05 ;{ }^{* *}$ Significant at $P<0.01$. THSNC1: Temperate humid \& subhumid Northeast China; WHSNC2: Warm-temperate humid \& subhumid North China; SHCSC3: Subtropical humid Central \& South China; 
590 Table 3 Percentage area of significant coherence (PASC, \%) of BWC between NDVI and single 591 climatic factor at different scales for grassland under six climatic regions.

\begin{tabular}{|c|c|c|c|c|c|c|c|}
\hline $\begin{array}{l}\text { Climatic } \\
\text { region }\end{array}$ & $\begin{array}{c}\text { Climatic } \\
\text { factor }\end{array}$ & $\leq 1$ years & $1-4$ years & $4-8$ years & $>8$ years & $\begin{array}{c}\text { Overall } \\
\text { temporal scales }\end{array}$ & $\begin{array}{l}\text { Type of Correlation } \\
\text { around } 1 \text { year }\end{array}$ \\
\hline \multirow{7}{*}{ THSNC1 } & MT & 34.46 & 40.79 & 1.12 & 0.00 & 27.97 & Positive \\
\hline & HT & 37.83 & 39.84 & 1.16 & 0.00 & 28.88 & Positive \\
\hline & LT & 29.96 & 41.69 & 2.37 & 0.00 & 26.13 & Positive \\
\hline & $\mathrm{AP}$ & 49.58 & 29.62 & 0.00 & 0.00 & 30.48 & Positive \\
\hline & SSD & 33.95 & 27.60 & 0.00 & 17.61 & 24.62 & Positive \\
\hline & RH & 48.40 & 29.24 & 4.49 & 0.00 & 30.15 & Positive \\
\hline & WS & 42.17 & 36.41 & 0.69 & 0.00 & 29.60 & Negative \\
\hline \multirow{7}{*}{ WHSNC2 } & MT & 33.90 & 39.47 & 3.57 & 11.34 & 28.50 & Positive \\
\hline & HT & 33.78 & 41.00 & 9.66 & 2.28 & 29.49 & Positive \\
\hline & $\mathrm{LT}$ & 32.80 & 39.92 & 1.12 & 22.97 & 28.85 & Positive \\
\hline & AP & 45.71 & 40.48 & 28.17 & 0.00 & 36.70 & Positive \\
\hline & SSD & 25.88 & 27.67 & 0.00 & 0.00 & 19.99 & Positive \\
\hline & RH & 34.33 & 27.31 & 0.00 & 0.00 & 23.08 & Positive \\
\hline & WS & 36.65 & 31.21 & 0.00 & 0.00 & 25.43 & Negative \\
\hline \multirow{7}{*}{ SHCSC3 } & MT & 23.26 & 26.03 & 0.00 & 0.00 & 18.33 & Positive \\
\hline & HT & 23.29 & 35.56 & 0.00 & 0.00 & 21.14 & Positive \\
\hline & LT & 22.60 & 27.01 & 0.00 & 0.00 & 18.27 & Positive \\
\hline & AP & 29.95 & 30.17 & 0.00 & 0.00 & 22.42 & Positive \\
\hline & SSD & 10.63 & 23.37 & 5.74 & 0.00 & 12.86 & Positive \\
\hline & RH & 22.86 & 25.38 & 0.00 & 0.00 & 17.82 & Positive \\
\hline & WS & 20.02 & 26.96 & 0.00 & 0.00 & 17.18 & Negative \\
\hline \multirow{7}{*}{ TGIM4 } & MT & 32.31 & 36.91 & 5.51 & 28.05 & 29.49 & Positive \\
\hline & HT & 36.11 & 35.80 & 6.82 & 50.63 & 30.74 & Positive \\
\hline & LT & 29.62 & 39.11 & 8.70 & 19.26 & 28.60 & Positive \\
\hline & $\mathrm{AP}$ & 51.71 & 53.03 & 49.65 & 44.33 & 51.15 & Positive \\
\hline & SSD & 29.94 & 31.59 & 2.59 & 0.00 & 23.41 & Positive \\
\hline & RH & 38.50 & 25.68 & 5.60 & 0.00 & 25.25 & Positive \\
\hline & WS & 38.03 & 34.94 & 16.50 & 0.00 & 29.92 & Negative \\
\hline \multirow{7}{*}{ TWDNC5 } & MT & 33.69 & 39.42 & 0.55 & 0.00 & 26.90 & Positive \\
\hline & HT & 31.00 & 38.93 & 1.53 & 0.00 & 25.64 & Positive \\
\hline & LT & 38.09 & 40.18 & 0.53 & 0.00 & 29.05 & Positive \\
\hline & AP & 30.61 & 50.95 & 33.15 & 3.82 & 35.62 & Positive \\
\hline & SSD & 28.53 & 45.27 & 12.50 & 0.00 & 28.75 & Positive \\
\hline & RH & 26.86 & 36.60 & 15.67 & 6.97 & 25.41 & Positive \\
\hline & WS & 32.90 & 32.38 & 0.00 & 5.25 & 25.09 & Negative \\
\hline \multirow{7}{*}{ TP6 } & MT & 39.17 & 43.25 & 2.55 & 25.35 & 32.80 & Positive \\
\hline & HT & 31.46 & 43.55 & 0.00 & 34.70 & 30.03 & Positive \\
\hline & LT & 43.60 & 41.95 & 32.11 & 0.00 & 37.98 & Positive \\
\hline & AP & 57.61 & 39.33 & 22.10 & 68.31 & 46.20 & Positive \\
\hline & SSD & 24.11 & 25.55 & 31.35 & 62.32 & 29.33 & Positive \\
\hline & RH & 23.97 & 15.82 & 13.68 & 0.00 & 17.57 & Positive \\
\hline & WS & 32.91 & 20.98 & 3.19 & 0.00 & 20.79 & Negative \\
\hline
\end{tabular}

592 The dominantly influencing factors at different scales are shown in bold. THSNC1: Temperate humid \& subhumid

593 Northeast China; WHSNC2: Warm-temperate humid \& subhumid North China; SHCSC3: Subtropical humid

594 Central \& South China; TGIM4: Temperate grassland of Inner Mongolia; TWDNC5: Temperate \& warm-temperate

595 desert of Northwest China; and TP6: Tibetan Plateau. 
Table 4 Percentage area of significant coherence (PASC, \%) of BWC between NDVI and single 598 climatic factor at different scales for cropland under six climatic regions.

\begin{tabular}{|c|c|c|c|c|c|c|c|}
\hline $\begin{array}{l}\text { Climatic } \\
\text { region }\end{array}$ & $\begin{array}{l}\text { Climatic } \\
\text { factor }\end{array}$ & $\leq 1$ years & $1-4$ years & $4-8$ years & $>8$ years & $\begin{array}{c}\text { Overall } \\
\text { Temporal scale }\end{array}$ & $\begin{array}{l}\text { Type of correlation } \\
\text { around } 1 \text { year }\end{array}$ \\
\hline \multirow{7}{*}{ THSNC1 } & MT & 37.97 & 39.41 & 12.42 & 10.57 & 31.67 & Positive \\
\hline & HT & 38.64 & 38.44 & 16.05 & 10.08 & 32.64 & Positive \\
\hline & LT & 33.67 & 40.65 & 10.01 & 15.09 & 30.19 & Positive \\
\hline & AP & 49.93 & 45.05 & 11.19 & 57.25 & 42.65 & Positive \\
\hline & SSD & 32.36 & 33.09 & 1.49 & 65.13 & 30.90 & Positive \\
\hline & RH & 25.10 & 9.95 & 0.00 & 0.00 & 13.55 & Positive \\
\hline & WS & 40.65 & 31.94 & 0.00 & 0.00 & 27.46 & Negative \\
\hline \multirow{7}{*}{ WHSNC2 } & MT & 29.74 & 42.70 & 0.00 & 22.65 & 28.92 & Positive \\
\hline & HT & 29.57 & 41.61 & 0.00 & 0.35 & 26.46 & Positive \\
\hline & LT & 32.78 & 40.07 & 6.27 & 40.16 & 31.76 & Positive \\
\hline & AP & 44.83 & 32.59 & 12.83 & 0.00 & 31.43 & Positive \\
\hline & SSD & 22.77 & 19.82 & 0.00 & 0.00 & 15.97 & Positive \\
\hline & RH & 22.87 & 20.65 & 4.11 & 0.00 & 17.13 & Positive \\
\hline & WS & 21.87 & 21.86 & 20.83 & 50.42 & 23.72 & Negative \\
\hline \multirow{7}{*}{ SHCSC3 } & MT & 30.98 & 37.44 & 6.31 & 16.81 & 27.58 & Positive \\
\hline & HT & 34.45 & 40.44 & 4.29 & 0.00 & 28.29 & Positive \\
\hline & LT & 28.49 & 34.26 & 3.49 & 19.96 & 26.25 & Positive \\
\hline & AP & 43.58 & 31.88 & 22.20 & 2.24 & 31.63 & Positive \\
\hline & SSD & 29.39 & 19.04 & 18.73 & 62.50 & 27.99 & Positive \\
\hline & $\mathrm{RH}$ & 27.54 & 26.62 & 5.35 & 0.00 & 21.07 & Positive \\
\hline & WS & 25.29 & 30.46 & 8.95 & 53.19 & 27.40 & Negative \\
\hline \multirow{7}{*}{ TGIM4 } & MT & 30.99 & 36.88 & 10.64 & 0.00 & 26.95 & Positive \\
\hline & HT & 34.25 & 37.25 & 14.11 & 2.21 & 28.83 & Positive \\
\hline & LT & 27.57 & 36.18 & 5.37 & 0.00 & 24.18 & Positive \\
\hline & AP & 43.41 & 30.85 & 0.00 & 0.00 & 28.16 & Positive \\
\hline & SSD & 26.41 & 36.28 & 8.54 & 0.00 & 24.02 & Positive \\
\hline & RH & 46.66 & 29.49 & 0.00 & 0.00 & 29.02 & Positive \\
\hline & WS & 40.31 & 27.08 & 1.14 & 0.00 & 26.07 & Negative \\
\hline \multirow{7}{*}{ TWDNC5 } & MT & 38.22 & 40.34 & 0.00 & 0.00 & 29.31 & Positive \\
\hline & HT & 36.44 & 39.97 & 0.00 & 0.00 & 28.21 & Positive \\
\hline & LT & 41.71 & 41.10 & 0.00 & 0.00 & 30.68 & Positive \\
\hline & $\mathrm{AP}$ & 29.88 & 33.66 & 1.59 & 0.00 & 23.68 & Positive \\
\hline & SSD & 24.79 & 30.89 & 0.00 & 0.00 & 20.01 & Positive \\
\hline & RH & 29.69 & 30.64 & 0.00 & 0.00 & 22.31 & Positive \\
\hline & WS & 44.05 & 35.96 & 0.00 & 0.00 & 30.26 & Negative \\
\hline \multirow{7}{*}{ TP6 } & MT & 35.57 & 40.76 & 14.97 & 7.70 & 32.56 & Positive \\
\hline & HT & 36.08 & 39.27 & 11.11 & 0.00 & 29.76 & Positive \\
\hline & LT & 36.74 & 40.64 & 21.53 & 50.00 & 36.69 & Positive \\
\hline & AP & 45.43 & 36.11 & 3.13 & 0.00 & 31.20 & Positive \\
\hline & SSD & 27.62 & 30.00 & 0.00 & 0.00 & 21.61 & Positive \\
\hline & RH & 35.86 & 26.99 & 4.60 & 0.00 & 24.60 & Positive \\
\hline & WS & 38.46 & 32.40 & 2.31 & 19.89 & 28.84 & Negative \\
\hline $\begin{array}{l}599 \\
600 \\
601 \\
602\end{array}$ & \multicolumn{7}{|c|}{$\begin{array}{l}\text { The dominantly influencing factors at different scales are shown in bold. THSNC1: Temperate humid \& subhumid } \\
\text { Northeast China; WHSNC2: Warm-temperate humid \& subhumid North China; SHCSC3: Subtropical humid } \\
\text { Central \& South China; TGIM4: Temperate grassland of Inner Mongolia; TWDNC5: Temperate \& warm-temperate } \\
\text { desert of Northwest China; and TP6: Tibetan Plateau. }\end{array}$} \\
\hline
\end{tabular}


603 Table 5 Percentage area of significant coherence (PASC, \%) of MWC between NDVI and

604 combined climatic factors at different scales under different climatic regions.

\begin{tabular}{|c|c|c|c|c|c|c|c|}
\hline $\begin{array}{l}\text { Vegetation } \\
\text { type }\end{array}$ & $\begin{array}{l}\text { Climatic } \\
\text { region }\end{array}$ & $\leq 1$ years & $1-4$ years & $4-8$ years & $>8$ years & $\begin{array}{c}\text { Overall } \\
\text { Temporal scale }\end{array}$ & $\mathrm{CV}^{\mathrm{d}}$ \\
\hline \multirow{7}{*}{ Grassland } & THSNC1 & $53.70(49.58)^{\mathrm{a}}$ & $43.00(40.79)^{\mathrm{a}}$ & $3.41(4.49)^{\mathrm{b}}$ & $90.48(17.61)^{\mathrm{a}}$ & $45.56(30.48)^{\mathrm{a}}$ & 75.18 \\
\hline & WHSNC2 & $48.92(45.71)^{\mathrm{a}}$ & $49.84(41.00)^{\mathrm{a}}$ & $21.12(28.17)^{b}$ & $61.34(22.97)^{\mathrm{a}}$ & $45.88(36.70)^{\mathrm{a}}$ & 37.71 \\
\hline & SHCSC3 & $33.93(29.95)^{\mathrm{a}}$ & $51.70(35.56)^{\mathrm{a}}$ & $0.33(5.74)^{b}$ & $70.10(0.00)^{\mathrm{a}}$ & $37.66(22.42)^{\mathrm{a}}$ & 76.17 \\
\hline & TGIM4 & $50.26(51.71)^{b}$ & $58.35(53.03)^{\mathrm{a}}$ & $66.22(49.65)^{\mathrm{a}}$ & $93.17(44.33)^{\mathrm{a}}$ & $59.53(51.15)^{\mathrm{a}}$ & 27.80 \\
\hline & TWDNC5 & $41.01(38.09)^{\mathrm{a}}$ & $52.03(50.95)^{\mathrm{a}}$ & $4.47(33.15)^{\mathrm{b}}$ & $66.81(6.97)^{\mathrm{a}}$ & $41.10(35.62)^{\mathrm{a}}$ & 64.74 \\
\hline & TP6 & $53.81(57.61)^{\mathrm{b}}$ & $69.41(43.55)^{\mathrm{a}}$ & $67.61(32.11)^{\mathrm{a}}$ & $95.59(68.31)^{\mathrm{a}}$ & $65.06(46.20)^{\mathrm{a}}$ & 24.36 \\
\hline & $\mathrm{CV}^{\mathrm{c}}$ & 16.84 & 16.63 & 116.26 & 19.02 & 21.95 & - \\
\hline \multirow{7}{*}{ Cropland } & THSNC1 & $54.13(49.93)^{\mathrm{a}}$ & $45.80(45.05)^{\mathrm{a}}$ & $1.47(16.05)^{\mathrm{b}}$ & $99.75(65.13)^{\mathrm{a}}$ & $47.20(42.65)^{\mathrm{a}}$ & 80.08 \\
\hline & WHSNC2 & $49.70(44.83)^{\mathrm{a}}$ & $50.14(42.70)^{\mathrm{a}}$ & $10.83(20.83)^{b}$ & $73.35(50.42)^{\mathrm{a}}$ & $45.78(31.76)^{\mathrm{a}}$ & 56.35 \\
\hline & SHCSC3 & $50.22(43.58)^{\mathrm{a}}$ & $41.77(40.44)^{\mathrm{a}}$ & $11.56(22.20)^{b}$ & $99.75(62.50)^{\mathrm{a}}$ & $45.90(31.63)^{\mathrm{a}}$ & 72.00 \\
\hline & TGIM4 & $41.19(46.66)^{b}$ & $41.52(37.25)^{\mathrm{a}}$ & $1.06(14.11)^{\mathrm{b}}$ & $92.19(2.21)^{\mathrm{a}}$ & $39.62(28.83)^{\mathrm{a}}$ & 84.86 \\
\hline & TWDNC5 & $41.55(44.05)^{b}$ & $43.76(41.10)^{\mathrm{a}}$ & $6.31(1.59)^{\mathrm{a}}$ & $74.30(0.00)^{\mathrm{a}}$ & $39.65(30.68)^{\mathrm{a}}$ & 67.03 \\
\hline & TP6 & $50.94(45.43)^{\mathrm{a}}$ & $50.42(40.76)^{\mathrm{a}}$ & $16.95(21.53)^{b}$ & $73.46(50.00)^{\mathrm{a}}$ & $47.39(36.69)^{\mathrm{a}}$ & 49.38 \\
\hline & $\mathrm{CV}^{\mathrm{c}}$ & 11.11 & 8.70 & 77.66 & 15.01 & 8.22 & - \\
\hline
\end{tabular}

605 Number in bracket is the PASC of the leading single factor with NDVI.

$606{ }^{a}$ The combined effect of climatic factors is greater than the leading single-factor.

607 b The combined effect of climatic factors is less than the leading single-factor.

$608{ }^{\mathrm{c}}$ Coefficient of variance for PASC among different regions.

$609{ }^{\mathrm{d}}$ Coefficient of variance for PASC among different temporal scales.

610 THSNC1: Temperate humid \& subhumid Northeast China; WHSNC2: Warm-temperate humid \& subhumid North

611 China; SHCSC3: Subtropical humid Central \& South China; TGIM4: Temperate grassland of Inner Mongolia;

612 TWDNC5: Temperate \& warm-temperate desert of Northwest China; and TP6: Tibetan Plateau. 
Table 6 Characteristic scale (year) of each intrinsic mode function (IMF) of NDVI and the percent of variance (year) explained by each IMF and residue under different vegetation type and climatic regions.

\begin{tabular}{|c|c|c|c|c|c|c|c|c|c|}
\hline $\begin{array}{l}\text { Vegetation } \\
\text { type }\end{array}$ & & $\begin{array}{l}\text { Climatic } \\
\text { region }\end{array}$ & IMF1 & IMF2 & IMF3 & IMF4 & IMF5 & IMF6 & Residue \\
\hline \multirow{12}{*}{ Grassland } & \multirow{6}{*}{$\begin{array}{l}\text { Scale } \\
\text { (year) }\end{array}$} & THSNC1 & 0.99 & 3.00 & 6.92 & 8.16 & 24.56 & - & - \\
\hline & & WHSNC2 & 0.99 & 2.27 & 3.99 & 5.32 & 9.29 & - & - \\
\hline & & SHCSC3 & 0.97 & 2.15 & 3.94 & 7.77 & 11.61 & 12.73 & \\
\hline & & TGIM4 & 0.99 & 2.81 & 4.98 & 9.68 & - & - & - \\
\hline & & TWDNC5 & 0.99 & 3.24 & 5.35 & 9.31 & - & - & - \\
\hline & & TP6 & 1.00 & 2.99 & 5.25 & 7.81 & 10.78 & - & - \\
\hline & \multirow{6}{*}{$\begin{array}{c}\text { Percent } \\
\text { of } \\
\text { variance } \\
(\%)\end{array}$} & THSNC1 & 84.42 & 5.14 & 3.04 & 2.05 & 1.18 & - & 0.01 \\
\hline & & WHSNC2 & 82.52 & 5.17 & 3.12 & 2.01 & 1.42 & - & 2.35 \\
\hline & & SHCSC3 & 80.40 & 5.39 & 1.72 & 2.30 & 1.08 & 0.53 & 0.62 \\
\hline & & TGIM4 & 88.70 & 5.28 & 3.72 & 2.26 & - & - & 0.02 \\
\hline & & TWDNC5 & 88.49 & 5.29 & 3.30 & 2.18 & - & - & 0.43 \\
\hline & & TP6 & 89.69 & 4.05 & 3.04 & 2.04 & 0.61 & - & 0.05 \\
\hline \multirow{12}{*}{ Cropland } & \multirow{6}{*}{$\begin{array}{l}\text { Scale } \\
\text { (year) }\end{array}$} & THSNC1 & 1.00 & 3.01 & 4.92 & 7.85 & 17.78 & - & - \\
\hline & & WHSNC2 & 0.99 & 2.09 & 3.76 & 6.26 & 8.25 & 15.81 & - \\
\hline & & SHCSC3 & 0.99 & 2.42 & 4.19 & 6.28 & 14.27 & 15.39 & \\
\hline & & TGIM4 & 0.99 & 2.91 & 5.70 & 6.44 & - & - & - \\
\hline & & TWDNC5 & 0.99 & 2.99 & 7.62 & 10.13 & - & - & - \\
\hline & & TP6 & 0.99 & 2.47 & 4.67 & 7.41 & 11.61 & - & - \\
\hline & \multirow{6}{*}{$\begin{array}{c}\text { Percent } \\
\text { of } \\
\text { variance } \\
(\%)\end{array}$} & THSNC1 & 88.02 & 5.18 & 3.03 & 2.02 & 1.01 & & 0.10 \\
\hline & & WHSNC2 & 86.79 & 4.13 & 2.14 & 2.11 & 1.29 & 0.64 & 0.77 \\
\hline & & SHCSC3 & 80.30 & 5.59 & 3.61 & 2.86 & 1.12 & 0.53 & 3.27 \\
\hline & & TGIM4 & 89.32 & 5.23 & 3.13 & 1.33 & - & - & 0.03 \\
\hline & & TWDNC5 & 88.29 & 5.24 & 2.04 & 2.67 & - & - & 0.34 \\
\hline & & TP6 & 88.02 & 5.07 & 1.08 & 2.07 & 1.06 & - & 0.48 \\
\hline
\end{tabular}


620 Fig. 1. (a) Geographic distribution of selected meteorological stations and natural climatic regions, 621 and (b) Vegetation types in China.

622 Fig. 2. Local wavelet spectrum of mean NDVI under two land types (grassland and cropland) in the 623 six climatic regions. X-axis represents the real time from 1981 to 2015; Y-axis represents temporal 624 scale in year. The solid black lines designate the variance of NDVI at a confidence level of $68 \%$, 625 and color bar represents strength of variance.

626 Fig. 3. BWC between NDVI and single climatic factor under grassland in the six climatic regions. $627 \mathrm{X}$-axis represents the real time from 1981 to 2015, and Y-axis represents temporal scale in year. The 628 solid black lines represent $95 \%$ confidence level, color bar represents strength of correlation, and 629 direction of arrow represents the type of correlation (right pointing arrows being positive and left 630 pointing arrows being negative).

631 Fig. 4. BWC between NDVI and single climatic factor under cropland in the six climatic regions. 632 Fig. 5. MWC between NDVI and seven-factor combination of MT, HT, LT, AP, SSD, RH, WS under 633 two vegetation types in the six climatic regions. Solid black lines represent significant coherence at 634 $95 \%$ confidence level. Solid white lines indicate NDVI variation at $68 \%$ confidence level. 
Fig. 1.

63

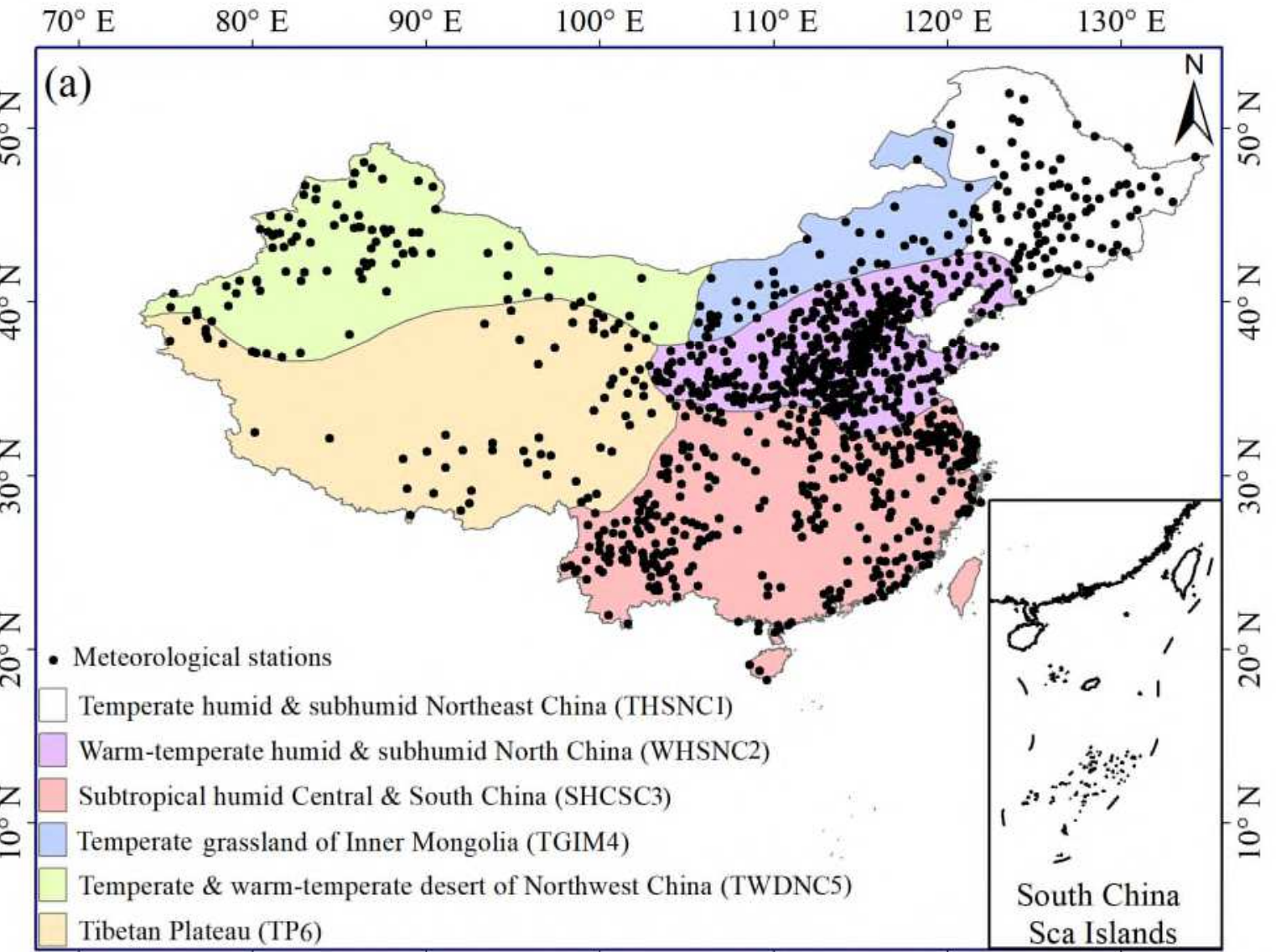

$\begin{array}{lllllll}70^{\circ} \mathrm{E} & 80^{\circ} \mathrm{E} & 90^{\circ} \mathrm{E} & 100^{\circ} \mathrm{E} & 110^{\circ} \mathrm{E} & 120^{\circ} \mathrm{E} & 130^{\circ} \mathrm{E}\end{array}$

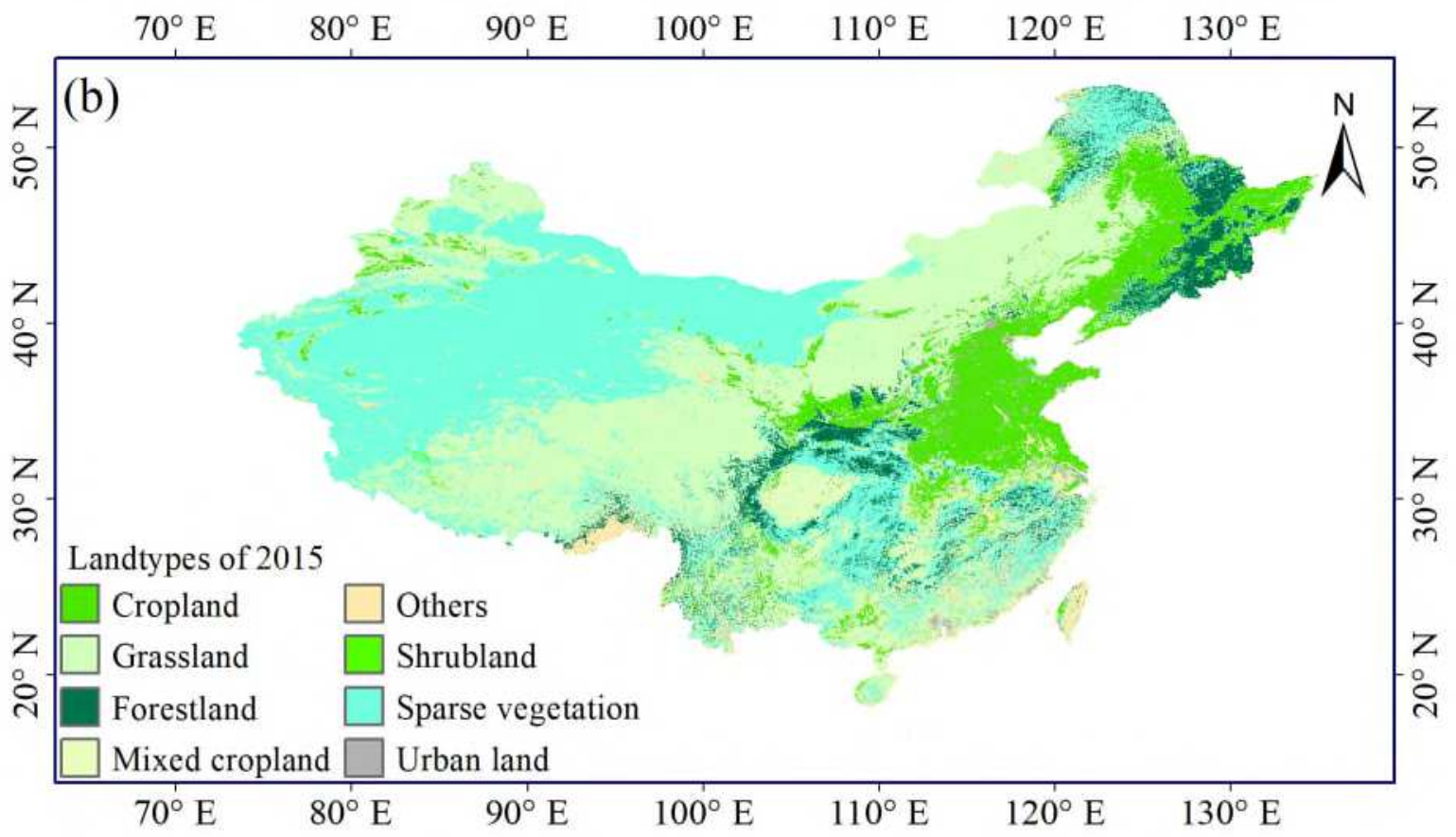


637 Fig. 2.

THSNCI

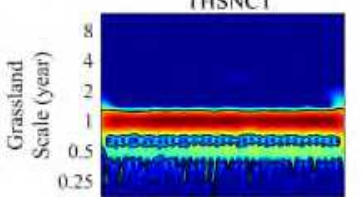

TGIM4
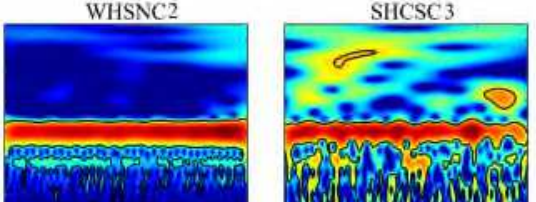

TWDNC5
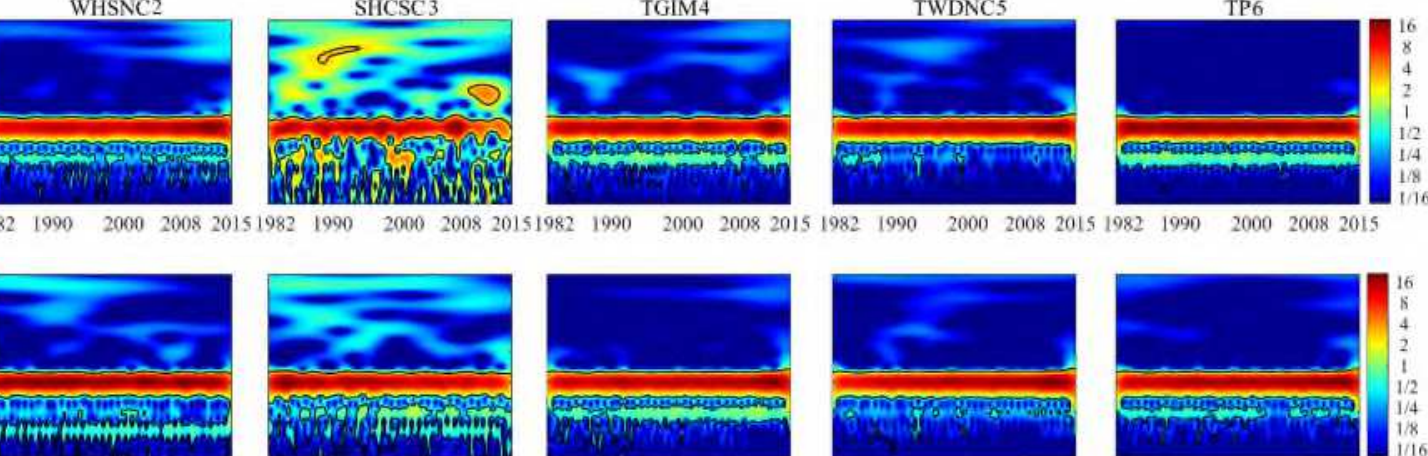

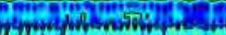


Fig. 3.
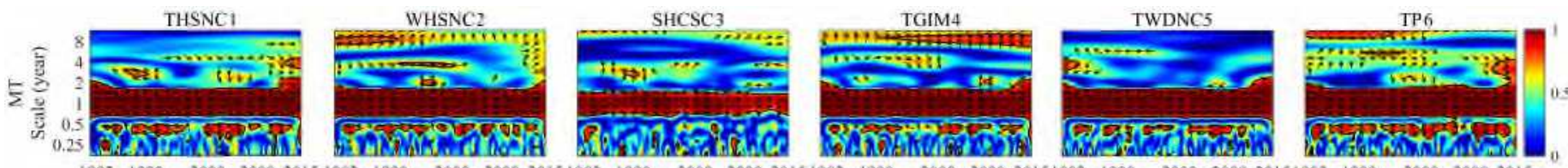

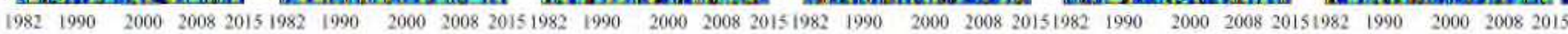
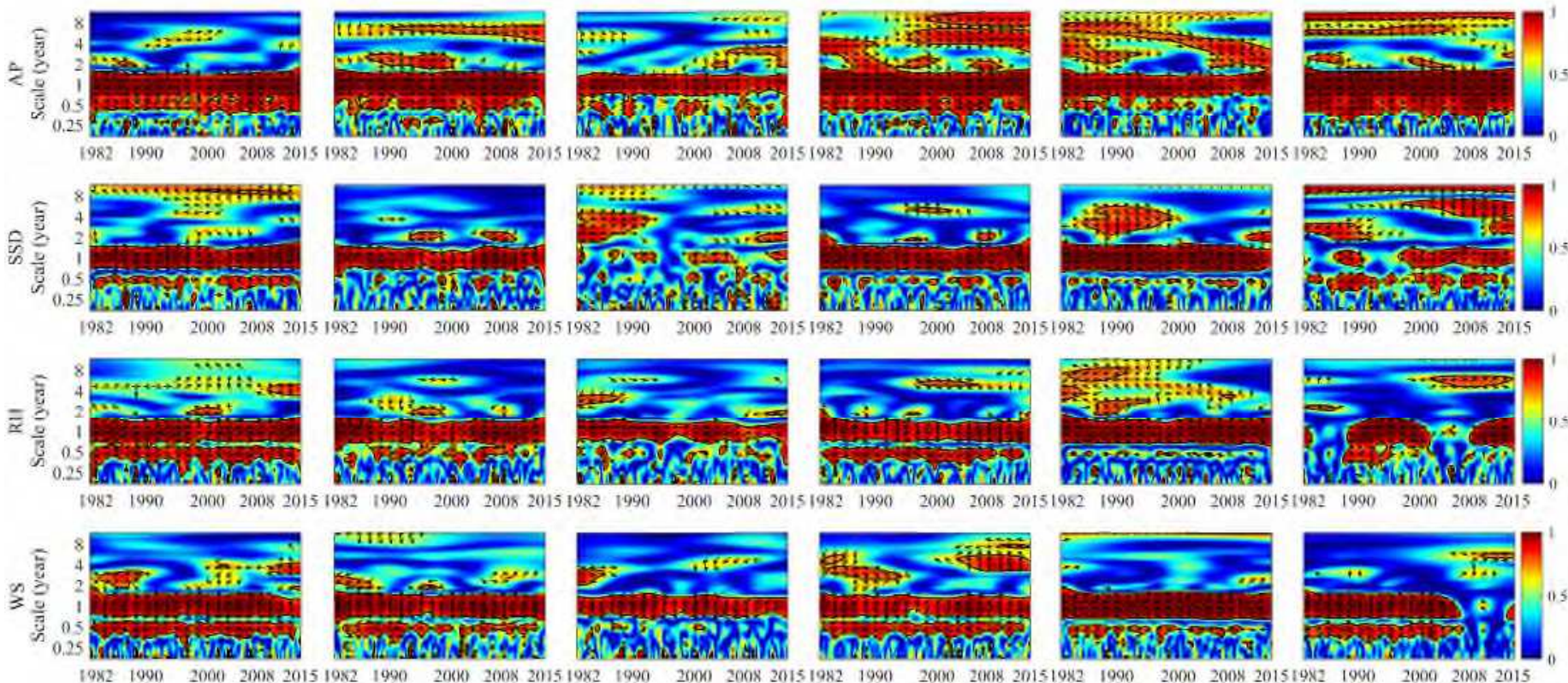

Time (year)

Time (year)

Time (year)

Time (year)

Time (year)

Time (year) 
641 Fig. 4.
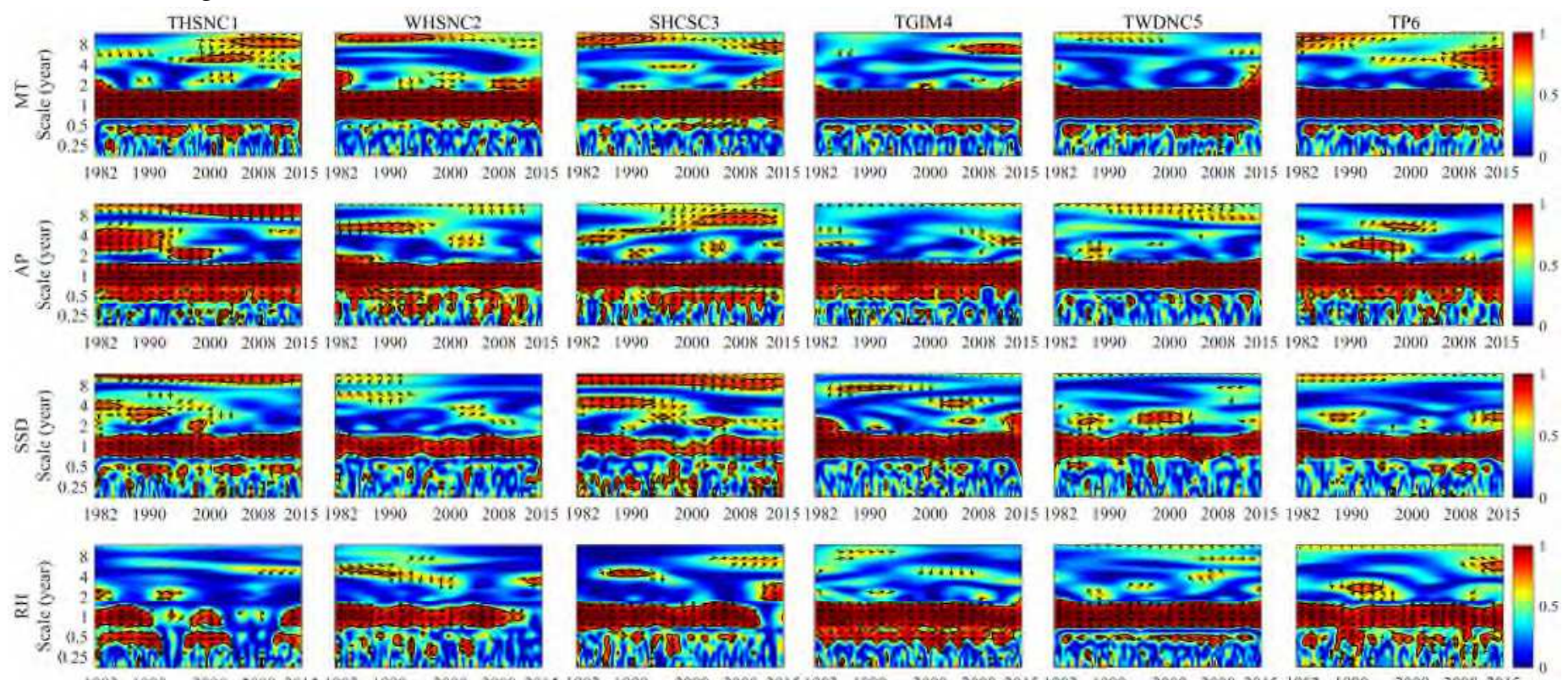

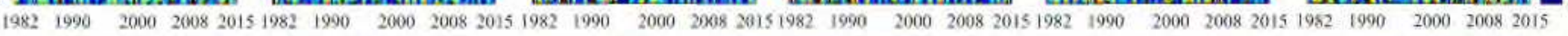
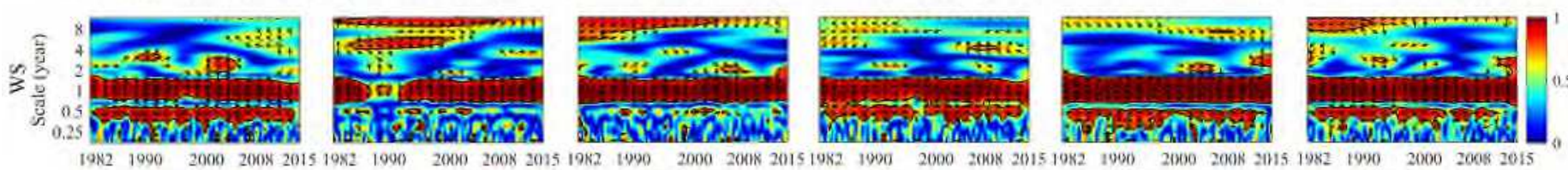

Time (year)

Time (year)

Time (year)

Time (year)

Time (year)

Time (year) 
643 Fig. 5.
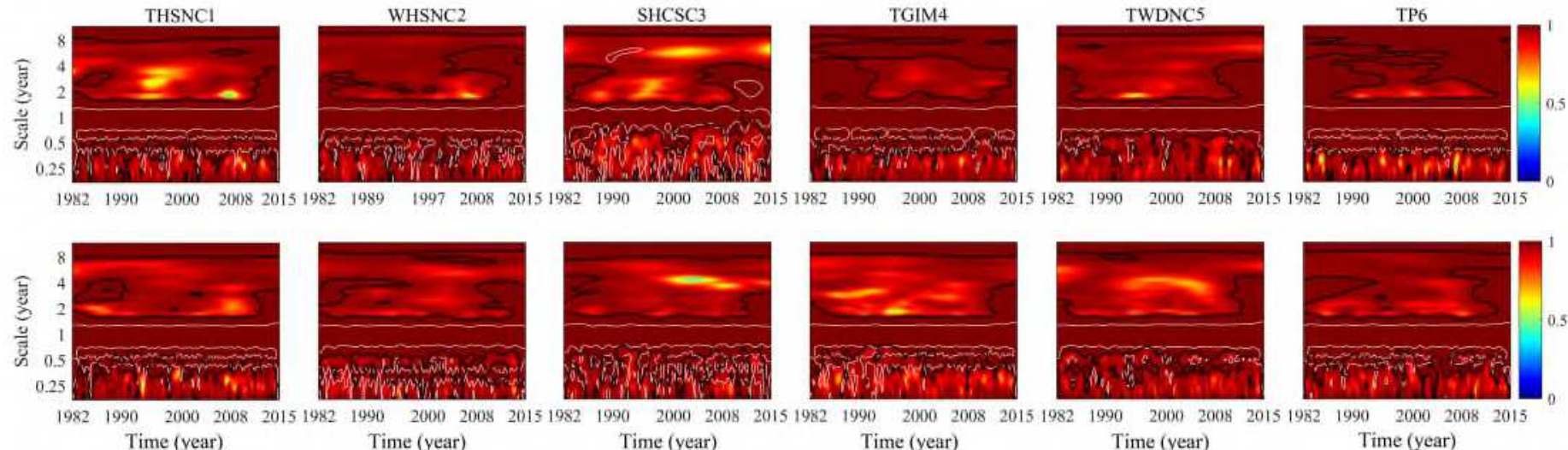

Time (year)

Time (year)

Time (year)

Time (year)

Time (year)

Time (year) 


\section{Supplementary Files}

This is a list of supplementary files associated with this preprint. Click to download.

- supplementaryfile.docx 